\title{
A EQUIPARAÇÃO DOS TRATADOS INTERNACIONAIS SOBRE MEIO AMBIENTE AOS TRATADOS DE DIREITOS HUMANOS
}

\section{THE EQUIVALENCE OF THE ENVIRONMENT INTERNATIONAL TREATIES TO THE HUMAN RIGHTS TREATIES}

\author{
Jonathan Alves Galdino ${ }^{1}$ \\ https://orcid.org/0000-0003-0084-6535 \\ José Adelson da Silva Miranda ${ }^{2}$ \\ https://orcid.org/0000-0001-5461-6757 \\ Adriano Fernandes Ferreira ${ }^{3}$ \\ https://orcid.org/0000-0001-6208-1430
}

Submissão: 04/06/2021 / Aceito: 14/07/2021 / Publicado: 13/08/2021

\begin{abstract}
Resumo
Tradicionais ferramentas internacionais de defesa dos direitos humanos positivaram direitos civis, econômicos, sociais, políticos e culturais sem alusão específica e expressa a direitos sobre o meio ambiente sadio. Assim, esta pesquisa objetivou avaliar a existência de equiparação entre tratados internacionais sobre meio ambiente com tratados de direitos humanos no ordenamento jurídico do Brasil, examinando a forma de integralização dos tratados internacionais sobre meio ambiente no direito brasileiro, bem como apontando o nível hierárquico que esses tratados ocupam no ordenamento jurídico brasileiro, por intermédio de pesquisa exploratória, descritiva, explicativa, documental, bibliográfica e telematizada, utilizando-se o método dedutivo. Verificou-se que, no Brasil, conforme a Constituição Federal de 1988 e a jurisprudência do Supremo Tribunal Federal (STF), tratados internacionais sobre meio ambiente podem ser equiparados a tratados internacionais de direitos humanos, ocupando uma hierarquia supralegal e constitucional no arcabouço legislativo doméstico brasileiro.
\end{abstract}

Palavras-chave: Tratados Internacionais. Direito ambiental. Direitos Humanos.

Abstract
Traditional international tools of human rights defense have positivized civil, economic, social, political and cultural rights without specific and express allusion to rights about healthy

\footnotetext{
${ }^{1}$ Mestre em Contabilidade e Controladoria e graduando em Direito pela Universidade Federal do Amazonas (UFAM). Contador no Ministério Público do Estado do Amazonas.

${ }^{2}$ Especialista em Direito Administrativo pela Universidade Cândido Mendes (UCAM). Bacharel em Direito pela Universidade Federal do Amazonas (UFAM).

3 Doutor em Ciências Jurídicas pela Universidade Castilla La Mancha (Espanha) e Pós-Doutor em Direito pela Universidade de Santiago de Compostela (Espanha). Mestre em Direito pela Universidade Gama Filho (UGF). Professor Adjunto IV da Universidade Federal do Amazonas (UFAM). Coordenador e Professor do Núcleo Permanente do Programa de Mestrado em Direito da UFAM e Professor do Programa de Pós-Graduação em Direito Ambiental da Universidade do Estado do Amazonas (UEA).
} 
environment. Therefore, this research aimed evaluating the existence of equivalation between international treaties about the environment and human rights treaties inside Brazilian legal system, examining the integration way of environment international treaties in Brazilian laws, as well as pointing out the hierarchical level that these treaties occupy on the Brazilian legal system, through exploratory, descriptive, explanatory, documentary, bibliographic and telematized research, using the deductive method. It was found that, in Brazil, according to the Federal Constitution of 1988 and the jurisprudence of the Supreme Federal Court (STF), international treaties on the environment can be compared to international human rights treaties, occupying a constitutional and supra legal hierarchy in the Brazilian domestic legislative framework.

Keywords: International treaties. Environment law. Human rights.

\section{INTRODUÇÃO}

O cuidado com o meio ambiente sadio, mormente com sua preservação e conservação, além de não ser um tema mundial novo, tem ganhado relevância cada vez maior no cenário internacional à medida que existe a consolidação constante de uma nova ordem mundial de interesses sociais com cunho ambientalista, amparada por normas ecológicas modernas de proteção e defesa do meio ambiente por parte da comunidade internacional em conjunto, com bases constitucionais, visando à construção de regramentos comuns a diversos Estados-nações, cujo objetivo e desafio atual é a racionalização do uso dos recursos naturais em prol do bem estar de seus povos (BENEDETTI, et al., 2016, p. 2).

Nesse talante, conforme os ensinamentos de Gloger (2018, p. 435), as ferramentas de garantias transnacionais possuem o ligeiro condão de relativizar a soberania de um Estado-nação e aplacar a autodeterminação dos povos ao adentrar nos ordenamentos jurídicos internos dos mais variados países, entre eles, o ordenamento jurídico brasileiro, constituindo-se em verdadeiras normas constitucionais e/ou supralegais dentro dessas nações.

Contudo, para que haja essa transnacionalidade das normas internacionais, incluindo as ambientais, foco deste estudo científico, proveniente da construção de regramentos ambientais comuns a nível internacional, é necessária a integralização delas ao direito interno de cada um dos países que a ratificam. Na prática brasileira, à guisa de exemplo, segundo o magistério de Mazzuoli (2015, p. 404) a integralização das normas internacionais ocorre quando um tratado internacional, em vigência no plano internacional, é ratificado, promulgado e publicado pelo Estado signatário, passando, assim, a integrar, o arcabouço normativo interno daquele ente e a produzir seus efeitos na ordem jurídica doméstica, sendo um deles o corolário de revogar as disposições legais em contrário ou incompatíveis com a norma infraconstitucional. 
Pode-se dizer que foi em 1972, durante a Conferência de Estocolmo, alcunhada de Conferência das Nações Unidas sobre o meio ambiente, que a pauta ecológica de preservação e conservação ambiental mundial entrou no debate internacional de maneira incipiente. Naquela ocasião, havia uma preocupação e uma importante discussão acerca dos resultados degradantes ao meio ambiente, decorrentes das ações humanas em busca frenética do progresso pelo progresso. Durante os debates e estudos desse evento internacional, concluiu-se que ações antrópicas estavam afetando demasiadamente o meio ambiente, o qual, por ser essencial para a sobrevivência da raça humana, deveria ser defendido não apenas pelos países industrializados desenvolvidos poluidores, mas também pelos países em desenvolvimento, os mais prejudicados pelas degradações climáticas. Daí em diante, o direito ao meio ambiente sadio, conservado e preservado se tornar pauta contumaz nos eventos internacionais da Organização das Nações Unidas (ONU) (NAZARETH e OBREGON, 2019, p. 3).

Se de um lado a pauta ambiental mundial não é nova e data da década de 70 (setenta) do século passado, por outro lado, os direitos humanos são muito mais antigos e sempre estiverem em discussão no âmbito internacional pós Segunda Grande Guerra. Segundo Mazzuoli (2002, p. 216 e 217) foi a partir do surgimento da ONU, em 1945, e da aprovação da Declaração Universal dos Direitos Humanos, em 1948, que os direitos humanos se consolidaram, concorrendo para a produção e patrocínio de variados tratados internacionais voltados para a proteção de garantias e direitos fundamentais.

Entretanto, de acordo Nazareth e Obregon (2019, p. 10), até a Conferência de Estocolmo em 1972, as ferramentas internacionais de proteção e defesa dos direitos humanos haviam positivado, no campo mundial, direitos civis, econômicos, sociais, políticos e culturais sem qualquer alusão específica e expressa a direitos relacionados à salvaguarda e preservação do meio ambiente sadio. Desse contexto, surge a seguinte questão de pesquisa: no ordenamento jurídico interno brasileiro, os tratados internacionais sobre meio ambiente são equiparados com os tratados de direitos humanos?

Dessa forma, busca-se com o presente estudo avaliar a existência ou não de equiparação entre os tratados internacionais sobre meio ambiente com os tratados de direitos humanos no ordenamento jurídico interno do Brasil, examinando a forma de integralização dos tratados internacionais sobre meio ambiente no direito brasileiro, bem como apontando o nível hierárquico que esses tratados ocupam no ordenamento jurídico brasileiro, por intermédio de pesquisa exploratória, descritiva e explicativa, quanto a seus fins, e pesquisa documental, bibliográfica e telematizada, quanto a seus meios, utilizando-se, ainda, o método dedutivo de pesquisa. 
Justifica-se, como dito, a relevância da presente reflexão pela sempre atual e relevante discussão sobre a seara ambiental, notadamente, quanto às suas repercussões no ordenamento jurídico interno do Brasil. Para a sua elaboração, este trabalho divide-se em 05 (cinco) seções, sendo esta a primeira de cunho introdutório; a próxima, de revisão de literatura, versando sobre uma breve contextualização histórica acerca da evolução do Direito Internacional em matéria de meio ambiente, bem como demonstrando a forma de ingresso dos tratados internacionais no ordenamento jurídico pátrio; a terceira seção descrevendo a metodologia empregada na consecução desta pesquisa científica; a quarta, demonstrando a análise de existência ou não de equiparação dos tratados internacionais sobre meio ambiente como tratado de direitos humanos no Brasil; e, por fim, a quinta seção de conclusão.

\section{CONTEXTO HISTÓRICO DA EVOLUÇÃo DO DIREITO AMBIENTAL NO ÂMBITO INTERNACIONAL}

Inicialmente, há de se ter como premissa básica a importância e necessária interdependência e indivisibilidade do meio ambiente e dos espaços a ele atinentes. Sabe-se que atrelado a isso, o meio ambiente e suas benesses e, inclusive, malefícios, são caros a todas as nações, independentemente da sua localização geográfica ou temporais.

Ou seja, o meio ambiente é um tema global, afeto a todas as nações, pertencente a todos os habitantes do planeta, sendo certo que a sua preservação e manutenção, com uso sustentável e equilibrado, importam não apenas àquela nação que detém em seu território determinado recurso, mas que qualquer interferência do homem na natureza, por certo, que influencia toda a coletividade mundial. Justamente por conta de todos esses fatores, o tema passou a ter relevância internacional e se iniciou o movimento ambiental internacional.

A Revolução Industrial, com suas intensas emissões de gases poluentes, serviu de primeiro alerta à preocupação com o fator ambiental; após, as previsões sempre faladas de que o crescimento demográfico, em progressão geométrica, não seria acompanhado do crescimento na produção de alimentos.

Todas as questões levaram a sociedade a se preocupar com questões que visavam atrelar os interesses sempre conflitantes, até então, ambientais e anseio pelo crescimento e desenvolvimento econômico, pelo que esse tema passou a figurar constantemente e passou a ser frequente objeto de diversos acordos e tratados internacionais, o que evidencia não só a natureza global da matéria, como a importância que lhe é ínsita. 
Em um primeiro instante, figurou como expecto maior a de que as nações incorporassem o tema ambiental aos seus ordenamentos pátrios, momento histórico no qual o direito ambiental se esgotava unicamente no campo da jurisdição estatal.

Posteriormente, reconhecendo-se a natureza difusa e interdependente entre todos os habitantes do planeta do tema ambiental, o titular do direito ambiental passou a ser a comunidade internacional, através da celebração de inúmeras convenções internacionais referentes ao meio ambiente. A despeito disso, a problemática surgida a partir dos referidos compromissos foi no sentido de que aqueles carecem de instrumentos de coerção.

Os primeiros tratados e acordos internacionais sobre o tema, nesse sentido, estavam revestidos de um caráter predominantemente econômico ou desenvolvimentista; na medida em que a preocupação com o meio ambiente exsurgiu unicamente como forma de garantir algum recurso ou atividade econômica.

Nesse contexto, diversos ajustes com enfoque na atividade pesqueira e na poluição, tais quais a Convenção sobre Pesca no Atlântico Norte (1959) e a Convenção Internacional sobre Responsabilidade Civil por Danos Causados por Poluição por Óleo (1969), respectivamente.

Para Accioly e Casella (2019) não é possível precisar o marco inicial do Direito Internacional Ambiental (ou Direito Internacional do Meio Ambiente). O ano de 1972, quando foi realizada a Conferência de Estocolmo, é apontado como o ano da tomada de conscientização para questões relativas à destruição do meio ambiente, em âmbito global.

Trata-se, na realidade, de um despertar tardio, dado que o modo com que se vinha até então lidando com o meio ambiente se confunde com a própria trajetória da humanidade. Ainda de acordo com os referidos autores, importante lembrar que, de maneira geral, as sociedades ocidentais não eram muito afeitas ao meio natural. Motivo pelo qual o padrão eurocêntrico de civilização, imposto aos mais variados povos do globo, foi a base de toda a indiferença em relação à natureza. Nesse contexto, tanto os povos indígenas na América quanto os reinos e tribos africanas e até mesmo algumas sociedades com história milenar e culturas tradicionais na Ásia, foram vistas como "selvagens", posto que o padrão europeu de civilização e progresso era inexoravelmente ligado à desvinculação do homem com o meio, com o ambiente natural (ACCIOLY; CASELLA, 2019).

Para Rezek (2019), assim como as normas vigentes atualmente no âmbito global sobre economia e desenvolvimento, as normas ambientais têm frequentemente um sentido de diretrizes de comportamento mais que de obrigações estritas de resultado, configurando assim aquilo que foi chamado por alguns de soft law. Para o autor, preocupações pontuais nesse sentido não seriam 
propriamente uma novidade. Isso porque tratados e decisões arbitrais, que datam do final do século XIX, têm claro teor preservacionista (num primeiro momento de espécies da fauna, depois da flora e dos rios).

Ainda segundo Rezek, esse direito esparso, nos idos dos anos 50, ocupou-se de prevenir algumas formas de poluição alarmantes para a época, como as decorrentes de indústrias mecânicas e químicas, bem como de atividades nucleares. A internacionalização da matéria ambiental se deu a partir de 1972, com a Conferência das Nações Unidas sobre o Meio Ambiente (Estocolmo), da qual resultaram diversas resoluções e recomendações, além da principal, qual seja: uma "Declaração de princípios que materializava as 'convicções comuns' dos Estados participantes” (REZEK, p. 147, 2019).

Ao final da Conferência, foi assinada a Convenção da Declaração sobre o Meio Ambiente Humano, constante de três documentos principais, quais sejam, a Declaração de Princípios de Estocolmo, o Plano de Ação para o Meio Ambiente e o Programa das Nações Unidas para o Meio Ambiente (PNUMA).

É importante destacar que a Declaração de Estocolmo, em seu princípio 24 reconhece a importância do tema na seara internacional e preceitua que: "a cooperação através de convênios multilaterais ou bilaterais [...] é essencial para efetivamente controlar, prevenir, reduzir e eliminar os efeitos desfavoráveis ao meio ambiente [...]”. Seguiram-se a esta, diversas outras Convenções que, igualmente, tinham por norte a proteção ambiental: a Convenção sobre Comércio Internacional de Espécies de Flora e Fauna Selvagens em Perigo de Extinção (CITES) (1973), a Convenção sobre Poluição Transfronteiriça (1979), a Convenção de Viena para a Proteção da Camada de Ozônio (1985), o Protocolo de Montreal sobre as Substâncias que Esgotam a Camada de Ozônio (1987), a Convenção sobre Controle de Movimentos Transfronteiriços de Resíduos Perigosos (Convenção da Basiléia, 1989).

A história do direito internacional ambiental tem início tal como se conhece hoje, de acordo com Accioly e Casella (2019), com a arbitragem entre os Estados Unidos e o Canadá, em virtude de poluição transfronteiriça, decorrente de fundição instalada em território do canadense, que ficou conhecida como Trail Smelter Case. Após esgotamento de todas as tentativas de conciliação e depois de inúmeras reclamações da população, residente na fronteira do estado de Washington (EUA) com o Canadá, por conta das emissões de gases tóxicos, que afetavam diretamente as pessoas do lado norte-americano, estes tomaram o problema como de estado, e iniciaram o procedimento arbitral em desfavor do Canadá. 
Em 1941 (ACCIOLY; CASELA, 2019), o desfecho teve como resultado o julgamento desfavorável ao Canadá, o qual trouxe, na parte final da sentença arbitral, a formulação de um princípio que é mencionado até hoje quando da elaboração de declarações e tratados internacionais, a saber:

\begin{abstract}
Nenhum estado tem o direito de usar ou permitir o uso de seu território de maneira tal que emanações de gases ocasionem danos dentro do território de outro estado ou sobre as propriedades ou pessoas que aí se encontrem, quando se trata de consequências graves e o dano seja determinado mediante prova certa e conclusiva.
\end{abstract}

No mesmo sentido, Mazzuoli (2019) afirma ter sido somente depois da segunda metade do séc. XX que as questões relativas à proteção da natureza ganharam importância no cenário internacional, sobretudo por conta da constatação de que o meio ambiente, ao contrário do que acontece com os Estados, não se divide por fronteiras. Os rios transfronteiriços, diz o autor, não mudam de cor ao cruzarem mais de um Estado, assim como as aves que os sobrevoam não necessitam de passaporte. A mesma situação é vista quando a poluição é levada pelo vento de um país a outro. Embora hoje essa constatação possa parecer por demais óbvia, nenhum pensador a anteviu antes do séc. XX.

No Rio de Janeiro, duas décadas após a Conferência de Estocolmo, em 1992, reuniu-se a Conferência das Nações Unidas sobre Meio Ambiente e Desenvolvimento. A importância conferida a esse empenho por parte da sociedade internacional ficou evidente com a participação de 180 delegações nacionais, 117 delas tendo à frente o próprio chefe de Estado ou de governo. Da conferência resultaram duas convenções - uma sobre mudanças climáticas e diversidade biológica —, e duas declarações - uma geral, outra sobre florestas - e um plano amplo de ação batizado de Agenda 21. Esses três últimos textos não possuíam natureza vinculante, e os anos futuros não foram nada animadores. Depois de cinco anos, a Assembleia Geral da ONU formalmente declarou o atraso na implementação incipiente da Agenda 21 (REZEK, 2019).

Oportuno salientar que os documentos oriundos da Conferência de 1992 deram o tom do que viria a ser o direito internacional ambiental a partir de então. Além das Convenções-Quadro sobre Mudança do Clima e sobre Diversidade Biológica, concebidas nos anos anteriores, mas que refletem o processo e as preocupações da Conferência de 1992, da Conferência resultou na adoção dos documentos não vinculantes, de acordo com Accioly e Casella (p. 273, 2019):

- Agenda 21 - documento propositivo, com a função de nortear políticas públicas dos estados em quatro áreas, quais sejam, aspectos sociais e econômicos do meio ambiente, conservação e exploração dos recursos naturais com vistas ao desenvolvimento, fortalecimento e participação de grupos importantes e formas de implementação; 


\begin{abstract}
- Declaração de Princípios sobre as Florestas - trata da exploração econômica de florestas, foi preparado sob a forma de declaração, em razão da falta de consenso entre as partes para celebração de tratado multilateral sobre a conservação das florestas tropicais;

- Declaração de Princípios sobre Meio Ambiente e Desenvolvimento - conjunto de princípios, a exemplo da Declaração de Estocolmo, não vinculantes, que, segundo avalia Guido F. S. SOARES, “a) consagram a filosofia da proteção dos interesses das presentes e futuras gerações; b) fixam os princípios básicos para uma política ambiental de abrangência global, em respeito aos postulados de um Direito ao Desenvolvimento, desde há muito reivindicados pelos países em vias de desenvolvimento; c) em decorrência dos mencionados princípios básicos, consagram a luta contra a pobreza, e recomendam uma política demográfica; e d) reconhecem o fato de a responsabilidade de os países industrializados serem os principais causadores dos danos já ocorridos ao meio ambiente mundial.
\end{abstract}

A criação da Comissão para o Desenvolvimento Sustentável, órgão das Nações Unidas vinculado ao ECOSOC, foi mais um importante resultado da Conferência de 1992. Sua principal função é realizar o acompanhamento da implementação da Agenda 21 e avanços das políticas voltadas à promoção do crescimento e desenvolvimento sustentável.

A partir da Rio-92, consideráveis mudanças aconteceram no cenário mundial, especialmente no tocante às evoluções tecnológicas, buscas irrefreáveis pelo crescimento e lucros, todos desvinculados de uma ideia sustentável, culminando na Conferência de Johanesburgo, em 2002, também conhecida como Fórum Mundial sobre Desenvolvimento Sustentável (Rio+10).

Esta Conferência ficou marcada por não ter apresentado os avanços esperados e planejados nas anteriores, Estocolmo-72 e Rio-92. Pelo contrário, houve por parte de vários países a instituição de barreiras e dificuldades quanto à implementação das metas preconizadas nas convenções e tratados anteriores, especialmente pela Agenda 21 firmada no Rio de Janeiro, dez anos antes.

O Acordo de Paris sobre mudança do clima, discutido em 12 de dezembro de 2015 e assinado em Nova York, no dia 22 de abril de 2016, é o mais novo tratado internacional de combate à mudança do clima.

Diferentemente do Protocolo de Kyoto, Paris não impõe metas quantitativas individuais para os países signatários reduzirem suas emissões de gases de efeito estufa, da mesma forma que não restringe as obrigações apenas aos países “desenvolvidos”. Prevê, então, que as metas dos países signatários serão por si determinadas, sendo obrigação de todos os países apresentar a sua contribuição e reportar periodicamente sobre seu desempenho. Aqui celebra-se um novo momento, a mitigação da mudança do clima através de dois enfoques: leis nacionais e transparência internacional.

Enfim, como se vê, o Brasil sempre adotou um papel ativo e de destaque na maioria das discussões e questões atinentes à seara ambiental internacional, sendo inclusive signatário dos principais tratados internacionais relativos ao meio ambiente de iniciativa da ONU. Inclusive, antes 
da promulgação da Constituição de 1988, já havíamos ratificado alguns dos mais importantes tratados relativos ao Direito Internacional do Meio Ambiente, vindo, tal postura, a intensificar-se após sua promulgação.

\section{A INTERNALIZAÇÃO DOS TRATAdOS INTERNACIONAIS NO BRASIL E A QUESTÃO DOS DIREITOS HUMANOS}

O conflito entre as normas internacionais e a ordem interna é assunto com forte debate entre doutrinadores e operadores do direito e, desde a assinatura dos primeiros tratados, têm demandado inúmeras discussões e ocupado espaços de debate acadêmico sobre as duas repercussões jurídicas. Resumidamente, o tema é abordado em duas correntes doutrinárias: o dualismo e o monismo.

A teoria dualista posiciona-se no sentido de não haver conflito possível entre o ordenamento interno e a ordem jurídica internacional, na medida em que ocupam e regulam esferas distintas, sem encontro possível; sendo certo que o direito internacional só é incorporado no ordenamento jurídico interno através de uma lei.

O monismo, por sua vez, percebe o ordenamento jurídico como uma unidade, razão pela qual exsurge a necessidade de coordenação entre as normas internacionais e as normas oriundas do ordenamento interno; pelo que o conflito entre normas dá ensejo ao surgimento de duas correntes, quais sejam, a predominância do direito internacional ou a que se posiciona pela prevalência do direito interno.

No cenário antecedente à promulgação da CF/1988, quando se tratava de conflito entre norma internacional e direito infraconstitucional, o monismo jurídico, com prevalência do direito internacional, é prevalente na doutrina brasileira.

A despeito disso, quando da análise de uma questão atinente ao tema, no Recurso Extraordinário - RE n. ${ }^{\circ} 80.004$ (Rel. Min. CUNHA PEIXOTO, julgado em 01/06/1977), o Supremo Tribunal Federal (STF) adotou o sistema paritário ou monismo nacionalista moderado, segundo o qual tratados e convenções internacionais possuem o status de lei ordinária e, quando nenhuma outra tratar da matéria, valem como tal.

Segundo André de Carvalho Ramos (2020), com a promulgação da Constituição de 1988, parte da doutrina se filiou à tese de que os tratados de direitos humanos gozavam de certo privilégio em relação aos demais tratados por conta da redação dos dois parágrafos originais do art. $5^{\circ}$. O $\S 1^{\circ}$ estabelece que "as normas definidoras dos direitos e garantias fundamentais têm aplicação imediata”. Esse termo "aplicação imediata” teria, para uma parcela da doutrina, como corolário a 
dispensa do decreto de promulgação. Em consequência disso, houve quem defendesse que, desde a Constituição de 1988, existiria um permissivo de dispensa da incorporação e uma adoção automática dos tratados internacionais de direitos humanos de que o Brasil fosse parte.

Assim, o ato de ratificação e a entrada em vigor, no plano internacional, do tratado de direitos humanos seriam suficientes para que este fosse, de forma automática, válido internamente. Não obstante isso, o STF interpretou o art. $5^{\circ}, \S 1^{\circ}$ de forma restritiva, para quem o referido artigo se referiria apenas à aplicação interna dos direitos e garantias fundamentais, portanto, sem relação com a necessidade ou não de decreto executivo na incorporação de tratados. Nesse sentido, de acordo com o STF, não houve qualquer alteração no processo de formação e incorporação dos tratados: todos — inclusive os de direitos humanos — devem se submeter às fases vistas acima: assinatura, decreto legislativo, ratificação e decreto presidencial, para que possam ter validade interna.

Para Valério Mazzuoli (2014), os tratados internacionais de direitos humanos ratificados pelo Brasil já possuem, tecnicamente, status de norma constitucional, em razão da redação dada pelo § 2..$^{\circ}$ do art. 5. ${ }^{\circ}$, da Constituição, que assim dispõe: "não excluem outros decorrentes do regime e dos princípios por ela adotados, ou dos tratados internacionais em que a República Federativa do Brasil seja parte", pois, se a Constituição "não exclui" os direitos humanos oriundos então é porque ela própria "os inclui" em seu rol de direitos protegidos, ampliando assim seu "bloco de constitucionalidade" e atribuindo-lhes hierarquia de norma constitucional. Assim, já se exclui o entendimento segundo o qual os tratados de proteção aos direitos humanos não aprovados pela maioria qualificada do $\S 3 .^{\circ}$ do art. 5..$^{\circ}$ teriam equivalência à lei ordinária federal, pelo fato (aparente) de eles terem sido aprovados apenas por maioria simples - na forma do art. 49, I, da Constituição — e não pelo quorum imposto pelo aludido parágrafo. Ora, não é possível admitir, diz o autor, a tese da paridade hierárquico-normativa para tratados que tenham conteúdo materialmente constitucional (a exemplo dos tratados de proteção aos direitos humanos). Saliente-se, por fim, que o $\S 3 .^{\circ}$ do art. 5. ${ }^{\circ}$ não confere status de lei ordinária aos tratados não aprovados por sua maioria qualificada.

Assim, passariam a ter tratamentos distintos os acordos internacionais que versavam sobre outras matérias. No caso de o objeto do tratado se tratar de direitos humanos, teria status constitucional; diferentemente de o tratado ser incorporado com status infraconstitucional e com paridade de hierarquia entre as leis ordinárias ou complementares, quando outros temas.

A despeito disso, em inúmeros julgados que se seguiram e a intensa discussão sobre a matéria, permaneceu se entendendo pelo status legal das normas internacionais de direitos humanos. 
Veja-se o Habeas Corpus - HC nº 72.131-RJ, julgado em 1995, em que o STF decidiu que em caso de conflito do tratado com lei nacional, este deve ser resolvido pelo critério cronológico combinado com o da especialidade (lex posterior generalis non derogat legi priori speciali).

O STF esclareceu que as normas internas que preconizavam a prisão do depositário fiel seriam normas gerais, não afastadas pelo tratado internacional. Entendeu-se que o Pacto San José da Costa Rica não suplantaria a Constituição Federal no ponto em que permite a prisão civil do depositário infiel.

Diante de toda a discussão e conflituosidade entre os entendimentos, acertados e melhor norteados da doutrina, diga-se, e a estrita legalidade aplicado pelo STF aos seus julgados, o poder constituinte derivado editou a Emenda Constitucional n. ${ }^{\circ} 45$, de 2004, em que se introduziu o parágrafo $3^{\circ}$ ao artigo $5^{\circ}$, da CF/1988, prevendo a possibilidade de que, se observado o procedimento de reforma constitucional, os tratados de direitos humanos seriam considerados como emendas constitucionais:

$\S 3^{\circ}$ Os tratados e convenções internacionais sobre direitos humanos que forem aprovados, em cada Casa do Congresso Nacional, em dois turnos, por três quintos dos votos dos respectivos membros, serão equivalentes às emendas constitucionais. (Incluído pela Emenda Constitucional $n^{\circ} 45$, de 2004).

Assim, como se depreende da leitura do $\S 3^{\circ}$, do art. $5^{\circ}$, o legislador reformador não incluiu qualquer ressalva no tocante aos tratados internacionais de direitos humanos assumidos anteriormente à inovação constitucional.

Foi então que, após a alteração constitucional, o STF, reanalisando a questão da prisão civil do depositário fiel, no julgamento do Recurso Extraordinário - $\mathrm{RE} \mathrm{n}^{\circ} 466.343$, conferiu aos tratados de direitos humanos um regime jurídico diferenciado.

A decisão da Corte, contudo, não foi unânime quanto à hierarquia do regime aplicável aos tratados de direitos humanos, vencendo a posição de que estes revestem-se de status supralegal, que teria influência derrogatória e inibitória com relação a outras normas do ordenamento jurídico interno. No entanto, os vencidos, Ministros Celso de Mello, Cesar Peluso, Ellen Grace e Eros Grau, entenderam pela hierarquia constitucional dos tratados de direitos humanos:

PRISÃO CIVIL. Depósito. Depositário infiel. Alienação fiduciária. Decretação da medida coercitiva. Inadmissibilidade absoluta. Insubsistência da previsão constitucional e das normas subalternas. Interpretação do art. $5^{\circ}$, inc. LXVII e $\S \S 1^{\circ}, 2^{\circ}$ e $3^{\circ}$, da CF, à luz do art. $7^{\circ}, \S 7$, da Convenção Americana de Direitos Humanos (Pacto de San José da Costa Rica). Recurso improvido. Julgamento conjunto do RE $n^{\circ} 349.703$ e dos HCs $n^{\circ} 87.585$ e $n^{\circ}$ 92.566. É ilícita a prisão civil de depositário infiel, qualquer que seja a modalidade do depósito. 
(STF - RE: 466343 SP, Relator: Min. CEZAR PELUSO, Data de Julgamento: 03/12/2008, Tribunal Pleno, Data de Publicação: DJe-104 DIVULG 04-06-2009 PUBLIC 05-06-2009 EMENT VOL-02363-06 PP-01106 RDECTRAB v. 17, n. 186, 2010, p. 29-165).

Assim, para o STF, até meados de 2008, o entendimento era no sentido que os tratados internacionais, quer versassem sobre direitos humanos ou não, gozariam do status de lei ordinária, independentemente da matéria a qual regulava o tratado internacional.

Ora, a despeito dos entendimentos e alteração da EC n. ${ }^{\circ} 45$ pelo Poder Constituinte Derivado, impende destacar: ao apontar um tratado como tendo status de norma constitucional, compreende considerar que ele integra o bloco de constitucionalidade material (e não formal) do texto Constitucional. Ou seja, ainda que não de forma expressa, ele é constitucional, não precisando ser veiculado necessariamente por uma emenda constitucional, o que significaria dizer que esse mesmo tratado já integra formalmente (além de materialmente) o texto constitucional.

Assim, é possível propor que os tratados se encontram divididos em: i) tratados sobre direitos humanos aprovados pelo disposto no $\S 3^{\circ}$ do art. $5^{\circ}, \mathrm{CF} / 1988$, com hierarquia constitucional; ii) tratados de direitos humanos sem atendimento ao rito do $\S 3^{\circ}$ do art. $5^{\circ}$ ou anteriores a EC 45 , com hierarquia supralegal, estando acima da lei ordinária ou (a depender do entendimento) com hierarquia constitucional, por força do $\S 2^{\circ}$, do art. $5^{\circ}$ e iii) tratados que não versam sobre direitos humanos, guardando estrita relação de paridade normativa com as leis ordinárias, segundo o entendimento do STF, desde a década de 70.

\section{Procedimentos Metodológicos}

Conforme a taxionomia proposta por Vergara (2011, p. 44-45), este trabalho científico possui caráter exploratório, descritivo e explicativo quanto aos seus fins, não somente em virtude de sua natureza de sondagem, sem comportar hipóteses, e por visar a expor características de determinados fenômenos jurídicos, mas também pelo fato de que se pretendeu, com ele, esclarecer fatores que contribuem ou não para a existência dos fenômenos descritos.

A taxionomia acima ventilada, corroborada por Henriques e Medeiros (2004, p. 33), define a pesquisa exploratória como aquela que, ao estabelecer critérios, técnicas e métodos para formulação de uma pesquisa, objetiva fornecer informações acerca do objeto de pesquisa para orientar a elaboração de hipóteses; a pesquisa explicativa, por sua vez, como aquela que examina e interpreta os fatos, ou, in casu, os fenômenos jurídicos existentes na sociedade ao redor do 
pesquisador; e, por fim, a pesquisa descritiva, segundo aqueles autores, estuda, registra e analisa os fatos sociais sem que o pesquisador interfira diretamente neles.

Ainda segundo a taxionomia de Vergara (2011, p. 44-47), quantos aos meios de investigação utilizados, esta pesquisa pode ser classificada como documental, bibliográfica e telematizada, com a utilização de fontes de dados primários e secundários, vez que esta se utilizou de computador e Internet na busca desses dados, constituídos de documentos públicos oficiais e publicações baseadas em informações públicas, sendo desenvolvido também com fundamento em materiais bibliográficos tais como livros clássicos das áreas correlatas a desta pesquisa, bem como artigos científicos, dissertações e teses afins.

No que tange à natureza da pesquisa quanto aos dados utilizados, este estudo se caracteriza como uma pesquisa qualitativa, tendo em vista os seus procedimentos investigação não estatísticos, cuja característica é própria daquelas pesquisas consideradas quantitativas. Conforme mencionado e elucidado por Kripka, et al. (2015, p. 243), as pesquisas qualitativas contribuem para compreensão de um fenômeno no ambiente natural onde ele ocorre e dele faz parte, de maneira que o pesquisador passar a ser o instrumento principal na captação das informações sobre o referido fenômeno estudado.

De acordo com Flick (2009, p. 14 e 21), a pesquisa qualitativa tem enorme relevância para o estudo das relações sociais em razão da pluralização das esferas da vida. A pesquisa qualitativa trabalha, preponderantemente, com textos. Em breves palavras, pode-se considerar o processo de pesquisa qualitativa como um caminho de mão dupla, sendo uma mão no sentido da teoria ao texto e a outra mão, um caminho de volta, do texto à teoria.

É cediço que a produção de conhecimento científico não pode estar divorciada do emprego dos métodos científicos. Nesse sentido, emprestando-se as classificações de métodos científicos propostos por Marconi e Lakatos (2010, p. 65-88), cumpre dizer que o método científico utilizado para responder ao problema de pesquisa deste estudo foi o método dedutivo, pelo qual, parte-se de premissas maiores fundadas em leis e teorias já pré-existentes para descrever, explorar e explicar fenômenos particulares em uma conexão descendente. Disso decorre que, se todas essas premissas maiores, geralmente constantes da fundamentação teórica da pesquisa científica, são verdadeiras, logo, a conclusão a que se chega também deve ser. Caso contrário, ainda que apenas uma das premissas lançadas no estudo não seja verdadeira, a conclusão pode também assim não ser.

Dessa forma, a presente pesquisa avaliou a existência ou não de equiparação entre os tratados internacionais sobre meio ambiente com os tratados de direitos humanos no ordenamento jurídico 
interno do Brasil, a partir do exame da forma como os tratados internacionais sobre meio ambiente integralização são integralizados no direito brasileiro, tendo sido apontado o nível hierárquico que esses tratados ocupam no ordenamento jurídico brasileiro.

Este estudo se alinha, ainda, àqueles predominantes no campo das pesquisas científicas em Direito no Brasil, quais sejam: pesquisas descritivas acerca do ordenamento posto e dos conceitos dos dogmas dele constantes, sendo a reconstrução doutrinária desses dogmas, consubstanciada em categorizações para a organização lógica do arcabouço jurídico examinado, uma etapa imprescindível na produção do conhecimento e debate jurídico, geralmente, com apresentação de posicionamentos de diferentes doutrinadores sobre o fenômeno jurídico observado (FONSECA et al., 2008, p. 3979).

A coleta dos dados para a realização deste estudo científico ocorreu do período de 04/06/2020 a 15/06/2020. Para análise dos dados coletados, selecionaram-se as principais teorias e achados científicos, mormente em periódicos do "qualis" da Coordenação de Aperfeiçoamento de Pessoal de Nível Superior (CAPES). Por conseguinte, do dia 16/06/2020 ao dia 30/06/2020, realizou-se a leitura e a revisão da literatura inerente ao problema e aos objetivos de pesquisa, selecionada no âmbito da coleta de dados. A partir daí, do dia 01/07/2020 em diante, passou-se a estruturar e escrever esta produção científica, segundo os ditames da Associação Brasileira de Normas Técnicas (ABNT).

Por fim, insta dizer que a fragilidade desta pesquisa científica pode residir no seu caráter predominantemente jurídico-instrumental em relação ao seu caráter jurídico-científico, segundo a dicotomia explanada por Ximenes (2018, p. 8). Contudo, tal fragilidade não possui o condão de desabonar este trabalho, haja vista que as críticas às limitações das pesquisas jurídico-instrumentais em apenas "aprofundar" a leitura da norma já realizada pela "doutrina” e ao seu enfoque dogmático são perfeitamente contornáveis e solucionadas com aplicações da norma a um caso concreto (XIMENES, 2018, p. 11), como se fez neste estudo.

\section{RESULTADOS E DISCUSSÕES}

Após a revisão de literatura e a exposição da metodologia empregada na realização do presente trabalho, analisa-se e responde-se, nesta seção, a questão de pesquisa central acerca da equiparação ou não dos tratados internacionais sobre meio ambiente a envergadura de direitos humanos, no âmbito do ordenamento jurídico interno brasileiro. Senão, vejamos. 


\section{A equiparação dos direitos ao meio ambiente aos direitos humanos}

Nas lições de Mazzuoli (2015, p. 1092), a defesa do meio ambiente não é assunto reservado ao domínio exclusivo da legislação interna de cada nação, mas se constitui em dever a ser observado por toda comunidade internacional e não somente envolve os aspectos da preservação ambiental relativos à existência humana, mas também tem por objetivo a tutela do meio ambiente em virtude do direito à qualidade de vida sadia em todos os seus espectros, considerada, ainda, como um dos vieses do direitos fundamentais inerentes à pessoa humana.

Pois bem, antes da Declaração de Estocolmo sobre o Meio Ambiente Humano de 1972, os instrumentos internacionais garantidores de direitos humanos não traziam dispositivos específicos e expressos sobre direito relacionado ao meio ambiente sadio. Segundo ensina Silva $(2019$, p. 67), a Declaração de Estocolmo de 1972 foi a mola propulsora para que as Cartas Magnas de muitos Estados, entre eles o Brasil, reconhecessem, supervenientemente, o meio ambiente equilibrado, que, até então, era visto pela comunidade internacional como algo dissociado da humanidade, como um direito fundamental humano entre os direitos sociais dos homens.

Isso porque, no Princípio 01 da Declaração de Estocolmo sobre o Meio Ambiente Humano de 1972, houve o alçamento do direito ao meio ambiente à qualidade de direito humano fundamental, quando o referido dispositivo declaratório aduz que, in verbis, "O homem tem o direito fundamental à liberdade, à igualdade e ao desfrute de condições de vida adequadas, em um meio ambiente de qualidade tal que lhe permita levar uma vida digna [...]". Ademais, esse mesmo dispositivo declara que o homem, a quem esse direito se dirige, também é "portador solene" do dever de proteger e melhorar esse meio ambiente.

Com efeito, a evolução da interpretação do direito ao meio ambiente sadio a partir da Declaração de Estocolmo de 1972 deve ser compreendida, atualmente, em uma seara contextual de desenvolvimento sustentável, sob um prisma holístico e não pontual, de maneira que é impossível dissociar direitos humanos civis, sociais, culturais, econômicos e políticos da proteção e defesa ao meio ambiente e este último do desenvolvimento econômico (NAZARETH e OBREGON, 2019, p. 9).

Cançado Trindade (apud NAZETH; OBREGON, 2019, p. 9 e 10) realiza importante contribuição acadêmico-científica, por meio de suas pesquisas, ao ressaltar a intrínseca correlação forte entre a efetivação de direitos sociais, culturais, econômicos, políticos e civis com o direito ao 
meio ambiente, sob o argumento de que direitos sobre meio ambiente são extensão daqueles demais citados anteriormente. Nesse sentido, esse autor defende que direitos humanos como o direito à vida e o direito à saúde, por exemplo, não podem ser interpretados sob um aspecto limitado tão somente ao existir ou à saúde física, devendo ser interpretado extensivamente como direitos a condição de vida digna advinda de um indispensável meio ambiente sadio. Em mais, ventila o autor que até mesmo o direito à paz poderia ser interpretado extensivamente e estaria interligado ao direito ao meio ambiente sadio, pois, este último está associado ao direito humano ao desenvolvimento e satisfação das necessidades básicas humanas de modo que, em conclusão, é preciso, nesse diapasão, reconhecer os direitos sobre proteção e defesa do meio ambiente para que haja o fortalecimento da proteção dos direitos humanos.

Esse posicionamento se perfilha ao de Benedetti et al. (2017, p. 3) de que o direito ao meio ambiente sadio ou, em outras palavras, ecologicamente equilibrado poderia ter uma interpretação extensiva do direito à vida, constante do art. $3^{\circ}$ da Declaração Universal dos Direitos Humanos de 1948, consubstanciando-se em um direito à qualidade de vida sadia como conditio sine qua non à existência digna da vida humana, nos seguintes termos: "Toda pessoa tem direito à vida, à liberdade e à segurança pessoal [...]". De acordo com essas autoras, no termo "à vida" do referido dispositivo, o meio ambiente equilibrado está albergado, por não ser possível desvencilhar uma coisa da outra. Esse entendimento é reforçado por Machado; e Chacon e Cruz (apud BENEDETTI et al., 2017, p. 3). Daí, alguns autores, como Mazzuoli (2015, p. 1091), afirmarem que a matéria de proteção ao meio ambiente, na comunidade internacional, ter sua gênese na Declaração Universal dos Direitos Humanos de 1948, de modo não expresso, por óbvio, como na Declaração de Estocolmo de 1972.

Pois bem, como consequência das recomendações oriundas da Conferência de Estocolmo de 1972, primeiro evento oficial da ONU voltado para discussão acerca da preservação e conservação ambiental, e no espírito de cooperação para criação de um direito ambiental internacional, a República Federativa do Brasil, no início da década de 1980, passou a promulgar leis importantes de tutela e salvaguarda do meio ambiente, sendo uma delas e que encontra-se em vigor até hoje, a Lei Federal nº 6.938/1981, a qual não só dispôs sobre a Política Nacional do Meio Ambiente, seus fins e mecanismos de formulação e aplicação, mas também criou ferramentas de preservação e reparação de danos ao meio ambiente e cuidou da responsabilização civil por atos lesivos ao meio ambiente. Desde então, houve a produção de diversas disposições legais inerentes à defesa, preservação e conservação do meio ambiente enquanto bem jurídico internacional até culminar na 
Constituição Federal brasileira de 1988, a qual dedicou um capítulo inteiro sobre o tema (TANNOUS; GARCIA, 2008, p. 187).

Conforme mencionado anteriormente, a Constituição da República Federativa do Brasil de 1988 detém um capítulo inteiro dedicado ao meio ambiente, em seu artigo 225, inserindo nele, expressamente, em seu caput, a garantia fundamental de que, in verbis, "todos têm direito ao meio ambiente ecologicamente equilibrado", bem como impondo ao Poder Público e à coletividade o dever da sua defesa e preservação para as presentes e futuras gerações. Em seu $\S 1^{\circ}$, inclusive, há a previsão de uma série de deveres do Poder Público essenciais à efetivação dos direitos descritos no caput desse artigo, dentre eles, a definição dos espaços territoriais e seus componentes a serem especialmente protegidos; a exigência de estudo de impacto ambiental quando da potencialidade ensejadora de danos ambientais de alguma atividade; o controle de produção das substâncias danosas ao meio ambiente; promoção da educação ambiental; proteção da fauna e flora, entre outros.

Assim, assegurar o meio ambiente ecologicamente equilibrado, resguardado, puro e preservado, guarda estreita relação com a saúde e o bem-estar da população. Garantir o meio ambiente significa garantir vida digna de toda a população e aqui, não apenas de um dado Estado, mas de todo o planeta. Segundo o magistério do professor Mazzuoli (2015, p. 1096), o sobredito dispositivo legal constitucional consagra um princípio no ordenamento jurídico brasileiro de acordo com o qual o meio ambiente protegido e sadio é um direito humano fundamental que visa a defender o direito à vida em todos os seus desdobramentos, pois, sem ele, a pessoa humana não se realizaria plenamente, ou, lado outro, gozo pleno e sadio do direito à vida.

Os direitos humanos, assim, antes de qualquer fato, servem para proteger e, acima de tudo, assegurar e efetivar o princípio norteador de toda relação humana, que é o da dignidade da pessoa humana. Desse modo, prever no seu texto legal, de forma expressa, diversos deveres ao Poder Público e atribuições de responsabilidades no manejo da questão ambiental, como a Constituição Federal brasileira de 1988 faz, apenas confirma a natureza de direitos humanos dos direitos ambientais na legislação doméstica do Brasil.

Por isso, é inquestionável que o direito ao meio ambiente se apresenta como de status de direito humano e serve para assegurar o direito fundamental à vida. A questão já foi analisada pelo STF, tendo, em julgamento da Medida Cautelar em Ação Direta de Inconstitucionalidade - MCADI n $3.450-1$, expressamente abordado a questão, nos seguintes termos: 
METAINDIVIDUALIDADE - DIREITO DE TERCEIRA GERAÇÃO (OU DE NOVÍSSIMA DIMENSÃO) QUE CONSAGRA O POSTULADO DA SOLIDARIEDADE - NECESSIDADE DE IMPEDIR QUE A TRANSGRESSÃO A ESSE DIREITO FAÇA IRROMPER, NO SEIO DA COLETIVIDADE, CONFLITOS INTERGENERACIONAIS - ESPAÇOS TERRITORIAIS ESPECIALMENTE PROTEGIDOS (CF, ART. 225, $\S 1^{\circ}$, III)- ALTERAÇÃO E SUPRESSÃO DO REGIME JURÍDICO A ELES PERTINENTE MEDIDAS SUJEITAS AO PRINCÍPIO CONSTITUCIONAL DA RESERVA DE LEI SUPRESSÃO DE VEGETAÇÃO EM ÁREA DE PRESERVAÇÃO PERMANENTE POSSIBILIDADE DE A ADMINISTRAÇÃO PÚBLICA, CUMPRIDAS AS EXIGÊNCIAS LEGAIS, AUTORIZAR, LICENCIAR OU PERMITIR OBRAS E/OU ATIVIDADES NOS ESPAÇOS TERRITORIAIS PROTEGIDOS, DESDE QUE RESPEITADA, QUANTO A ESTES, A INTEGRIDADE DOS ATRIBUTOS JUSTIFICADORES DO REGIME DE PROTEÇÃO ESPECIAL - RELAÇÕES ENTRE ECONOMIA (CF, ART. $3^{\circ}$, II, C/C O ART. 170, VI) E ECOLOGIA (CF, ART. 225)COLISÃO DE DIREITOS FUNDAMENTAIS - CRITÉRIOS DE SUPERAÇÃO DESSE ESTADO DE TENSÃO ENTRE VALORES CONSTITUCIONAIS RELEVANTES - OS DIREITOS BÁSICOS DA PESSOA HUMANA E AS SUCESSIVAS GERAÇÕES (FASES OU DIMENSÕES) DE DIREITOS (RTJ 164/158, 160-161) -A QUESTÃO DA PRECEDÊNCIA DO DIREITO À PRESERVAÇÃO DO MEIO AMBIENTE: UMA LIMITAÇÃO CONSTITUCIONAL EXPLÍCITA À ATIVIDADE ECONÔMICA (CF, ART. 170, VI)- DECISÃO NÃO REFERENDADA - CONSEQÜENTE INDEFERIMENTO DO PEDIDO DE MEDIDA CAUTELAR. A PRESERVAÇÃO DA INTEGRIDADE DO MEIO AMBIENTE: EXPRESSÃO CONSTITUCIONAL DE UM DIREITO FUNDAMENTAL QUE ASSISTE À GENERALIDADE DAS PESSOAS.

- Todos têm direito ao meio ambiente ecologicamente equilibrado. Trata-se de um típico direito de terceira geração (ou de novíssima dimensão), que assiste a todo o gênero humano (RTJ 158/205-206). Incumbe, ao Estado e à própria coletividade, a especial obrigação de defender e preservar, em benefício das presentes e futuras gerações, esse direito de titularidade coletiva e de caráter transindividual (RTJ 164/158-161). O adimplemento desse encargo, que é irrenunciável, representa a garantia de que não se instaurarão, no seio da coletividade, os graves conflitos intergeracionais marcados pelo desrespeito ao dever de solidariedade, que a todos se impõe, na proteção desse bem essencial de uso comum das pessoas em geral. Doutrina. A ATIVIDADE ECONÔMICA NÃO PODE SER EXERCIDA EM DESARMONIA COM OS PRINCÍPIOS DESTINADOS A TORNAR EFETIVA A PROTEÇÃO AO MEIO AMBIENTE.

- A incolumidade do meio ambiente não pode ser comprometida por interesses empresariais nem ficar dependente de motivações de índole meramente econômica, ainda mais se se tiver presente que a atividade econômica, considerada a disciplina constitucional que a rege, está subordinada, dentre outros princípios gerais, àquele que privilegia a "defesa do meio ambiente" (CF, art. 170, VI), que traduz conceito amplo e abrangente das noções de meio ambiente natural, de meio ambiente cultural, de meio ambiente artificial (espaço urbano) e de meio ambiente laboral. Doutrina. Os instrumentos jurídicos de caráter legal e de natureza constitucional objetivam viabilizar a tutela efetiva do meio ambiente, para que não se alterem as propriedades e os atributos que lhe são inerentes, o que provocaria inaceitável comprometimento da saúde, segurança, cultura, trabalho e bem-estar da população, além de causar graves danos ecológicos ao patrimônio ambiental, considerado este em seu aspecto físico ou natural. A QUESTÃO DO DESENVOLVIMENTO NACIONAL (CF, ART. $3^{\circ}$, II) E A NECESSIDADE DE PRESERVAÇÃO DA INTEGRIDADE DO MEIO AMBIENTE (CF, ART. 225): O PRINCÍPIO DO DESENVOLVIMENTO SUSTENTÁVEL COMO FATOR DE OBTENÇÃO DO JUSTO EQUILÍBRIO ENTRE AS EXIGÊNCIAS DA ECONOMIA E AS DA ECOLOGIA.

- O princípio do desenvolvimento sustentável, além de impregnado de caráter eminentemente constitucional, encontra suporte legitimador em compromissos internacionais assumidos pelo Estado brasileiro e representa fator de obtenção do justo equilíbrio entre as exigências da economia e as da ecologia, subordinada, no entanto, a invocação desse postulado, quando ocorrente situação de conflito entre valores constitucionais relevantes, a uma condição inafastável, cuja observância não comprometa 
nem esvazie o conteúdo essencial de um dos mais significativos direitos fundamentais: o direito à preservação do meio ambiente, que traduz bem de uso comum da generalidade das pessoas, a ser resguardado em favor das presentes e futuras gerações. O ART. $4^{\circ} \mathrm{DO}$ CÓDIGO FLORESTAL E A MEDIDA PROVISÓRIA N² 2.166-67/2001: UM AVANÇO EXPRESSIVO NA TUTELA DAS ÁREAS DE PRESERVAÇÃO PERMANENTE.

- A Medida Provisória no 2.166-67, de 24/08/2001, na parte em que introduziu significativas alterações no art. 4o do Código Florestal, longe de comprometer os valores constitucionais consagrados no art. 225 da Lei Fundamental, estabeleceu, ao contrário, mecanismos que permitem um real controle, pelo Estado, das atividades desenvolvidas no âmbito das áreas de preservação permanente, em ordem a impedir ações predatórias e lesivas ao patrimônio ambiental, cuja situação de maior vulnerabilidade reclama proteção mais intensa, agora propiciada, de modo adequado e compatível com o texto constitucional, pelo diploma normativo em questão.

- Somente a alteração e a supressão do regime jurídico pertinente aos espaços territoriais especialmente protegidos qualificam-se, por efeito da cláusula inscrita no art. $225, \S 1^{\circ}$, III, da Constituição, como matérias sujeitas ao princípio da reserva legal.

- É lícito ao Poder Público - qualquer que seja a dimensão institucional em que se posicione na estrutura federativa (União, Estados-membros, Distrito Federal e Municípios) - autorizar, licenciar ou permitir a execução de obras e/ou a realização de serviços no âmbito dos espaços territoriais especialmente protegidos, desde que, além de observadas as restrições, limitações e exigências abstratamente estabelecidas em lei, não resulte comprometida a integridade dos atributos que justificaram, quanto a tais territórios, a instituição de regime jurídico de proteção especial $\left(\mathrm{CF}\right.$, art. $225, \S 1^{\circ}$, III).

(STF - ADI-MC: 3540 DF, Relator: CELSO DE MELLO, Data de Julgamento: 01/09/2005, Tribunal Pleno, Data de Publicação: DJ 03-02-2006 PP-00014 EMENTA VOL-02219-03 PP-00528)

Na esteira, o Pleno do STF, em oportunidade anterior, nos autos do Mandado de Segurança - MS nº 22.164-0/SP, da relatoria do Ministro Celso de Mello, reafirma a posição acima, ao declarar que o direito ao meio ambiente íntegro, o qual se constitui em direito típico de terceira geração, é prerrogativa jurídica, cuja titularidade é coletiva, e que, no âmbito do processo de afirmação dos direitos humanos, configura-se na relevante expressão de um poder atribuído não a uma individualidade singular de um sujeito, mas sim a uma coletividade social em geral em um sentido mais amplo.

Na esteira, nos autos do sobredito Mandado de Segurança - MS nº 22.164-0/SP, o Pleno do STF elucida que, nos direitos tidos como de primeira geração, que são direitos civis e políticos, estão albergadas as liberdades clássicas, negativas ou formais, ou seja, são direitos que destacam o ideal de liberdade, herança dos pensamentos iluministas e da Revolução Francesa de 1789; e, nos direitos de segunda geração, que são direitos sociais, econômicos e culturais, onde se encontram as denominadas liberdades positivas, concretas ou reais, e que são direitos ressaltantes do ideal de igualdade; e, por derradeiro, nos direitos de terceira geração, onde se encontram os direitos sobre meio ambiente no Brasil, são direitos que "materializam poderes de titularidade coletiva atribuídos genericamente a todas as formações sociais”, consagrando o princípio da solidariedade e 
constituindo-se em um relevante processo não só de fomente, como também de reconhecimento e expansão de direitos humanos, de natureza indisponível em face da sua essencialidade e perenidade.

A despeito de posições jurisprudenciais contrárias, que apelam para o formalismo exacerbado, nos termos do artigo $5^{\circ}, \S 2^{\circ}$ da Constituição Federal brasileira de 1988, os direitos e garantias nela expressos, não excluem outros decorrentes "dos tratados internacionais em que a República Federativa do Brasil seja parte”, pelo que os tratados internacionais de proteção ao meio ambiente enquadram-se perfeitamente nesta disposição constitucional.

Desta feita, verifica-se, de forma clara e irrefreável, que o direito ao meio ambiente sadio, equilibrado, resguardado, puro e preservado se reveste de caráter e se mostra como sendo de direito humano, dado a forte correlação que aquele apresenta para a garantia de não apenas de vida, isto é, de simplesmente existir, mas ainda de uma vida digna de pessoa humana.

A conclusão acima é coadunada por outros autores em estudos científicos próprios. À guisa de exemplo, Miller (2014, p. 54-55), por meio de pesquisa explicativa, bibliográfica e descritiva, objetivando identificar o tratamento dispensado ao direito a um meio ambiente sadio no plano internacional e nacional, concluiu, entre outras achados científicos, que, no plano doméstico brasileiro, tanto a Constituição Federal de 1988 quanto o próprio STF, Corte superior brasileira guardiã da Constituição Federal, consideram os tratados internacionais de direitos sobre meio ambiente como direitos humanos fundamentais, em posição hierárquica superior às leis ordinárias por via de consequência lógica.

Outrossim, é imperioso trazer a lume o fato de que não somente a Constituição Federal da República Federativa do Brasil que equipara direitos ambientais internacionais ao status de direitos humanos fundamentais em sua legislação doméstica. Segundo ressaltam Benedetti et al. (2016, p. 4), Constituições de países como Argentina, Uruguai e Paraguai são uníssonas em asseverar que a vida e o meio ambiente sadio e equilibrado são direitos interrelacionados de todos, cuja proteção é de interesse geral. Outro ponto em comum, segundo as autoras, é a adesão expressa ao princípio do desenvolvimento sustentável pelas Constituições do Brasil, da Argentina e, em parte, do Paraguai, mas sem previsão expressa na do Uruguai. Nesse diapasão, as autoras arrematam a inferência de que a defesa da vida e do ambiente sadio, como direito humano fundamental, é exigência comum das Cartas Magnas dos países membros do Mercosul, mutatis mutandis. 


\section{CONSIDERAÇÕES FINAIS}

Este estudo objetivou a avaliação da existência ou não de equiparação entre os tratados internacionais sobre meio ambiente com os tratados de direitos humanos no ordenamento jurídico interno do Brasil, a partir do exame da forma como os tratados internacionais sobre meio ambiente integralização são integralizados no direito brasileiro, tendo sido apontado o nível hierárquico que esses tratados ocupam no ordenamento jurídico brasileiro.

Por meio de pesquisa exploratória, descritiva e explicativa quanto aos seus fins, e documental, bibliográfica e telematizada, quanto aos seus meios, com abordagem qualitativa e fontes de dados primários e secundários, utilizando-se, ainda, o método dedutivo, verificou-se que direitos sobre meio ambiente, no âmbito internacional, são considerados direitos de terceira geração no âmbito interno brasileiro e que a Constituição Federal brasileira de 1988, ao reservar um capítulo inteiro para tratar do assunto, declarando o meio ambiente sadio como direito de todos e dever do Poder Público, em conjunto da doutrina e da jurisprudência colacionada do STF, que é a instância judiciária máxima no Brasil no que diz respeito ao julgamento de questões constitucionais, direitos sobre meio ambiente, na legislação doméstica brasileira, podem ser equiparados como direitos humanos fundamentais em uma intepretação extensiva do direito à vida, assim como ocorrem nas Constituições de países do Mercosul.

Disso, conclui-se, em adição, que, por estarem equiparados a direitos humanos fundamentais no ordenamento jurídico interno do Brasil, os direitos sobre o meio ambiente no plano legislativo nacional brasileiro, incluindo os tratados internacionais sobre meio ambiente dos quais o Brasil é signatário, ocupam um patamar supralegal e de matéria constitucional na hierarquia legislativa brasileira.

A vida é inequivocamente um direito fundamental e, nossa Constituição Federal de 1988 ao prever que o meio ambiente ecologicamente equilibrado é "essencial à sadia qualidade de vida", sendo dever do Poder Público a sua preservação, promoção e cuidado, impondo obrigações, deveres e sanções a quem dele desrespeitem, consubstancia o fino extrato para caracterização como sendo um direito humano. O texto constitucional brasileiro consagra o princípio segundo o qual o meio ambiente é um direito humano fundamental, e, portanto, sem ele o ser humano não se realiza plenamente.

Assim, de posições jurisprudenciais contrárias, que apelam para o formalismo exacerbado, nos termos do artigo $5^{\circ}, \S 2^{\circ}$ da Constituição Federal brasileira de 1988, os direitos e garantias nela 
expressos, não excluem outros decorrentes "dos tratados internacionais em que a República Federativa do Brasil seja parte", pelo que os tratados internacionais de proteção ao meio ambiente enquadram-se perfeitamente nesta disposição constitucional.

Os tratados internacionais de âmbito ambiental, assim, passam a deter a mesma proteção de direitos no mesmo plano de eficácia e igualdade daqueles direitos, expressa ou implicitamente, consagrados pelo texto constitucional. Ou seja, passam a ser considerados como se estivessem escritos na Constituição e a violação de tais tratados constitui não só em responsabilidade internacional do Estado, mas também na violação da própria Constituição que os alçou à categoria de normas constitucionais.

\section{REFERÊNCIAS}

ACCIOLY, Hildebrando; SILVA, Geraldo Eulálio do Nascimento; CASELLA, Paulo Borba. Manual de direito internacional público. 17. ed. São Paulo: Saraiva, 2009.

ACCIOLY, Hildebrando; SILVA, Geraldo Eulálio do Nascimento; CASELLA, Paulo Borba. Manual de direito internacional público. 24. ed. São Paulo: Saraiva educação, 2019.

BENEDETTI, Andrea Regina de Morais; CAPELLARI, Marta Botti; FRIEDRICH, Tatyana Scheila. O ambiente como direito humano e a tutela jurídica ambiental no Mercosul. Revista de Direito Ambiental, São Paulo, v. 03, pp. 1-11, jul./set. 2016.

BRASIL. Constituição (1988). Constituição da República Federativa do Brasil. Texto constitucional promulgado em 5 de outubro de 1988. Disponível em: http://www.planalto.gov.br/ccivil_03/constituicao/constituicaocompilado.htm. Acesso em: 28 jun. 2021.

BRASIL. Declaração de Estocolmo Sobre o Ambiente Humano. Disponível em: http://www.mma.gov.br. Acesso em: 05 ago. 2016.

BRASIL. SUPREMO TRIBUNAL FEDERAL. Recurso Extraordinário nº 80.004, Rel. Min. CUNHA PEIXOTO, julgado em 01/06/1977.

BRASIL. SUPREMO TRIBUNAL FEDERAL. Habeas Corpus $\mathrm{n}^{\circ}$ 72.131-RJ, julgado em 1995.

BRASIL. SUPREMO TRIBUNAL FEDERAL. Recurso Extraordinário nº 466343 SP, Relator: Min. CEZAR PELUSO, Data de Julgamento: 03/12/2008, Tribunal Pleno, Data de Publicação: DJe-104 DIVULG 04-06-2009 PUBLIC 05-06-2009 EMENT VOL-02363-06 PP-01106 RDECTRAB v. 17, n. 186, 2010, p. 29-165.

BRASIL. SUPREMO TRIBUNAL FEDERAL. Medida Cautelar em Ação Direta de Inconstitucionalidade ADI-MC: 3540 DF, Relator: CELSO DE MELLO, Data de Julgamento: 
01/09/2005 - Tribunal Pleno, Data de Publicação: DJ 03-02-2006 PP-00014 EMENTA VOL02219-03 PP-00528.

BRASIL. SUPREMO TRIBUNAL FEDERAL. Mandado de Segurança Cível - MS: 22164-0 SP, Relator: CELSO DE MELLO, Data de Julgamento: 30/10/1995 - Tribunal Pleno, Data de Publicação: DJ 17-11-1995 PP-39206 EMENT VOL-01809-05 PP-01155.

FLICK, Uwe. Introdução à pesquisa qualitativa. 3.ed. Porto Alegre: Artmed, 2009.

FONSECA, Dirce Mendes da; CIARALLO, Gilson; CRUZ, Tânia Cristina. Epistemologia do campo jurídico: reflexões acerca do papel da pesquisa jurídica. In: ENCONTRO NACIONAL DO CONSELHO NACIONAL DE PESQUISA E PÓS-GRADUAÇÃO EM DIREITO, 17., 2008, Salvador. Anais eletrônicos. Florianópolis: Fundação Boiteux, 2008. Disponível em: http://www.publicadireito.com.br/conpedi/manaus/arquivos/anais/salvador/dirce_mendes_da_fons eca.pdf. Acesso em: 28 jun. 2021.

GLOGER, Cássia Daiane Maier. Transnacionalismo, influência das normas internacionais no ordenamento jurídico brasileiro: proteção aos portadores de deficiência. Revista Jurídica LusoBrasileira, Lisboa, n. 4, a. 4, pp. 431-442, 2018.

HENRIQUES, Antônio; MEDEIROS, João Bosco. Monografia no curso de direito: como elaborar o trabalho de conclusão de curso (TCC). 4. ed. São Paulo: Atlas, 2004.

KRIPKA, Rosana Maria Luvezute; SCHELLER, Morgana; BONOTTO, Danusa de Lara. Pesquisa documental: considerações sobre conceitos e caraterísticas na pesquisa qualitativa. In: CONGRESSO IBERO-AMERICANO EM INVESTIGAÇÃO QUALITATIVA, 4., 2015, Aracaju. Anais eletrônicos. Aveiro: CIAIQ, 2015. Disponível em: https://proceedings.ciaiq.org/index.php/ciaiq2015/article/view/252/248. Acesso em: 28 jun. 2021.

MARCONI, Marina de Andrade; LAKATOS, Eva Maria. Fundamentos de metodologia científica. 7. ed. São Paulo, Atlas, 2010.

MAZZUOLI, Valério de Oliveira (Org.). Coletânea de Direito Internacional. 2. ed., ampl. São Paulo: Revista dos Tribunais, 2004.

MAZZUOLI, Valério de Oliveira. Curso de Direitos Humanos. Rio de Janeiro: Forense; São Paulo: MÉTODO, 2014.

MAZZUOLI, Valério de Oliveira. Curso de Direito Internacional Público. 9. ed. São Paulo: Revista dos Tribunais, 2015.

MAZZUOLI, Valério de Oliveira. Direitos Humanos, Constituição e os Tratados Internacionais. São Paulo: Juarez de Oliveira, 2002.

MILLER, Laura Martins. Direito ao meio ambiente sadio e o tratamento jurídico dos tratados de direito ambiental no ordenamento brasileiro. 2014. 60 f. Monografia (Especialização em Direito Ambiental Nacional e Internacional), Faculdade de Direito da Universidade Federal do Rio Grande do Sul, Porto Alegre, 2014. 
NAZARETH, Johanna Reinholz de Nazareth; Marcelo Fernando Quiroga Obregon. A inserção do direito ao meio ambiente sadio no rol dos direitos humanos. Revista Derecho y Cambio Social, pp. 92-110, 2019.

RAMOS, André de Carvalho. Curso de Direitos Humanos. 7. ed. São Paulo: Saraiva Educação, 2020.

REZEK, José Francisco. Direito Internacional Público: curso elementar. 15. ed. rev. e atual. São Paulo: Saraiva, 2014.

SILVA, José Afonso da. Direito Ambiental Constitucional. 11. ed. São Paulo: Malheiros, 2019.

TANNOUS, Simone; GARCIA, Anice. Histórico e evolução da educação ambiental, através dos tratados internacionais sobre o meio ambiente. Revista Nucleus, Ituverava, v. 5, n. 2, p. 183-196, 2008.

VERGARA, Sylvia Constant. Projetos e Relatórios de Pesquisa em Administração. 13. ed. São Paulo: Atlas, 2011.

XIMENES, Júlia Maurmann. Por que o problema continua sendo o problema? Diferenciando pesquisa jurídico-instrumental e pesquisa jurídico-científica e o papel das fontes do Direito.

Revista Direito Público, Porto Alegre, v. 15, n. 82, pp. 197-213, 2018. 